\title{
Cranial nerve palsies in tetanus: cephalic tetanus
}

\author{
D. M. PARK \\ From the Department of Neurology, United Oxford Hospitals
}

In a small proportion of cases of tetanus, a cranial nerve palsy is apparent, either as a presenting sign or developing in the course of the disease. This variant has been called cephalic tetanus, and its features have been variously described as comprising causative injury to the head, face or neck, dysphagia, and cranial nerve palsy with or without signs of more generalized tetanus. Such a case was reported in 1830 by Sir Charles Bell, and, in 1847, a fatal case by Pollock. In 1869, Rose in Zurich described a form of tetanus after head wounds, which might be associated with facial paralysis but was marked by the presence of hydrophobia. This syndrome he referred to as Kopftetanus. When, in 1912, Brown reviewed 94 cases in the world literature, the syndrome had acquired the name of cephalic tetanus. Subsequent reports (Watkins, 1939; Jayme-Goyaz, 1941 ; Wetzel, 1942; etc.) prompted Bagratuni (1952) to define cephalic tetanus as a form of the disease occurring after injury to the head or neck and associated with cranial nerve palsy. However, Patel, Dhirwani, and Mehta (1960), Vakil, Tulpule, Iyer, and Tulpule (1964) and Jaffari (1966) have shown that cranial nerve palsies may occur in tetanus when the site of injury is other than in the head and neck, and indeed when there is no apparent site of entry of infection. Argument has continued as to the aetiology of this condition, but there can be little doubt that the occurrence of a palsy of a cranial nerve, in a disease noted for the production of hypertonicity and spasticity, remains a curious and contradictory feature.

The purpose of this paper is to consider seven cases with cranial nerve signs, four of which are described in detail, occurring out of a total of 107 cases of tetanus treated at the United Oxford Hospitals since 1950, and to discuss the mechanism of production of the palsies.

\section{MATERIAL}

One hundred and seven cases of tetanus have been treated at the United Oxford Hospitals between 1950 and 1968, mostly in the Respiration Unit. Ten cases had had injury to the head, including one which developed after dental extraction; two further cases were otogenic that is, associated with otorrhoea; one case was postabortal, $18(16.8 \%)$ developed without clear evidence for the site of entry of infection, and all other cases developed in association with injury to the extremities. Seventy per cent of the patients were male, about $40 \%$ of the cases were classed as severe, and the mortality was $21.5 \%$.

The seven patients with cranial nerve palsies comprising the series had ages ranging between $4 \frac{1}{2}$ and 66 years. Five were male and two female. Six patients had had wounds in the face. The remaining case was associated with otorrhoea, and Clostridium tetani was isolated in this case only. Paralysis affected the face in five pa? tients, and the tongue in the otogenic case. (Five othero of the 107 patients had a site of entry in the head, bu䢖 no cranial nerve palsy was definitely recorded.) Nystag $\frac{7}{0}$ mus was present in two cases and was not attributabio to treatment. It was also noted in two other patient $\overrightarrow{0}$ with injury to the extremities. Ophthalmoplegia wás present in one case. All of them had trismus; tetanus was graded as severe in three, moderate in three, and mild in one. Tetanus was graded as 'severe', when generalized spasms occurred with a severity or frequency which endangered breathing. 'Mild' cases were those that did not develop generalized spasms and did not develop dysphagia. All seven patients made a complete recovery (Table).

The three severe cases do not appear in the following descriptions, since curarization abolished the evidence of cranial nerve palsy, and the striking feature of these cases was not the cranial nerve palsy itself but the severity of the generalized disease.

CASE 3 A 16-year-old youth sustained an injury from a hockey stick on the left side of the forehead. About two weeks later, he noticed progressive difficulty in opening his mouth and weakness of the left side of the face. Shortly afterwards he began to bite his tongue involuntarily and was admitted elsewhere. A piece of wood was removed from the original wound, but no further treatment was given. The diagnosis of tetanus was made and he was transferred to Oxford. On admission, three weeks after injury, he had, in addition to signs of mild tetanus, a left facial weakness which was curiously much more marked in the frontalis muscle. He was 
TABLE

CRANIAL NERVE PALSIES IN TETANUS

\begin{tabular}{|c|c|c|c|c|c|c|c|c|}
\hline $\begin{array}{l}\text { Case } \\
\text { no. }\end{array}$ & $\begin{array}{l}\text { Age } \\
(\operatorname{sex})\end{array}$ & $\begin{array}{l}\text { Presumed site } \\
\text { of entry }\end{array}$ & $\begin{array}{l}\text { Incubation } \\
\text { period }\end{array}$ & $\begin{array}{l}\text { Onset } \\
\text { period }\end{array}$ & $\begin{array}{l}\text { Cranial nerve } \\
\text { signs }\end{array}$ & $\begin{array}{c}\text { Grade } \\
\text { (see text) }\end{array}$ & Treatment & Complications \\
\hline 1 & $7 \mathrm{M}$ & R. temple & 4 days & $\begin{array}{l}\text { Less than } \\
24 \mathrm{hr}\end{array}$ & $\begin{array}{l}\text { R. VII } \\
\text { weakness }\end{array}$ & Severe & $\begin{array}{l}\text { Curare } \\
\text { IPPV }\end{array}$ & $\begin{array}{l}\text { Collapse } \\
\text { R. upper lobe }\end{array}$ \\
\hline 2 & $13 \mathrm{M}$ & $\begin{array}{l}\text { L. eyelid } \\
\text { foreign body }\end{array}$ & 8 days & $\begin{array}{l}\text { Less than } \\
24 \mathrm{hr}\end{array}$ & $\begin{array}{l}\text { L. VII } \\
\text { weakness }\end{array}$ & Severe & $\begin{array}{l}\text { Curare } \\
\text { IPPV }\end{array}$ & $\begin{array}{l}\text { Pneumothorax, } \\
\text { segmental collapse } \\
\text { R. upper lobe }\end{array}$ \\
\hline 3 & $16 \mathrm{M}$ & L. frontal & 2 weeks & - & $\begin{array}{l}\text { L. VII } \\
\text { weakness }\end{array}$ & Mild & $\begin{array}{l}\text { Mephenesin } \\
\text { chlorpromazine }\end{array}$ & - \\
\hline 4 & $4 \frac{1}{2} M$ & L. frontal & 5 days & $\begin{array}{l}\text { Less than } \\
24 \mathrm{hr}\end{array}$ & $\begin{array}{l}\text { L. VII weakness } \\
\text { nystagmus }\end{array}$ & Severe & $\begin{array}{l}\text { Curare } \\
\text { IPPV }\end{array}$ & $\begin{array}{l}\text { Collapse } \\
\text { R. upper lobe }\end{array}$ \\
\hline 5 & $58 \mathrm{~F}$ & $\begin{array}{l}\text { R. ot it is media. } \\
\text { Foreign body }\end{array}$ & 7 days & 14 days & $\begin{array}{l}\text { R. XII } \\
\text { R. ptosis }\end{array}$ & Moderate & $\begin{array}{l}\text { Curare } \\
\text { IPPV }\end{array}$ & Depression \\
\hline 6 & $14 \mathrm{M}$ & $\begin{array}{l}\text { L. eye } \\
\text { (enucleated) }\end{array}$ & 6 days & 1 day & $\begin{array}{l}\text { R. III } \\
\text { L. VII complete } \\
\text { R. VII weakness }\end{array}$ & Moderate & $\begin{array}{l}\text { Tracheostomy, } \\
\text { amylobarbitone, } \\
\text { diazepam }\end{array}$ & - \\
\hline 7 & $66 \mathrm{~F}$ & $\begin{array}{l}\text { Chin } \\
\text { L. of centre }\end{array}$ & 6 days & 4 days & $\begin{array}{l}\text { L. VII weakness } \\
\text { nystagmus }\end{array}$ & Moderate & $\begin{array}{l}\text { Tracheostomy, } \\
\text { diazepam }\end{array}$ & - \\
\hline
\end{tabular}

All cases had trismus and all made a complete recovery. Onset period is the interval between first symptom and first generalized spasm or onset of dysphagia. None of the patients had previously been immunized against tetanus. IPPV: intermit tent positive pressure ventilation.

treated with mephenesin and sodium amytal, and later with chlorpromazine. After three weeks' treatment he had no further jaw spasms and was discharged with slight persisting generalized hypertonus. At this time there had been virtually complete resolution of the facial paresis, though weakness of left frontalis persisted. One month after discharge there was only minimal evidence of weakness in the frontalis.

CASE 5 A 58-year-old housewife had had a discharging right ear for six days when she developed mild trismus and a right ptosis. Two weeks later she had a pharyngeal spasm and on admission elsewhere she was found to have right otitis media, and a tongue which protruded to the right. She received local antibiotics and systemic penicillin, but no other treatment. She had increasing neck stiffness for the next 10 days and mild opisthotonic spasms. After some further pharyngeal spasms she was transferred under general anaesthesia to Oxford, where tracheostomy, curarization, and intermittent positive pressure ventilation (IPPV) were instituted. A foreign body was removed from the right ear and Clostridium tetani was grown from it. Curare was discontinued after eight days, and replaced by diazepam. Intermittent positive pressure ventilation was discontinued after 17 days. The weakness of the tongue gradually improved until, 13 days after her admission to Oxford, it was barely noticeable.

CASE 6 A 14-year-old schoolboy was admitted elsewhere after a laceration of the left eye caused by a stone fired from an airgun. The lens was removed and the laceration sutured. No tetanus prophylaxis was given. After three days the eye was obviously infected and had to be removed. He received local and systemic antibiotics. Three days later he had a left facial weakness and, by the following day, trismus and dysphagia. The diagnosis of tetanus was made and he was transferred to Oxford where, in addition to moderate tetanus, he was noted to have paralysis of upward gaze and restricted horizontal movement of the remaining eye. Right orbicularis oculis was weak in addition to the left facial weakness. Tracheostomy was performed; he received antibiotics, about 10,000 units of hyperimmune human antitetanus plasma, and was sedated with amylobarbitone and diazepam. The following day he had a right ptosis and a poorly reacting myotic pupil. The eye movements were unchanged. After a further six days the facial weakness had recovered, and the eye movements were improving. After 30 days at Oxford he was discharged with a persisting mild defect of upward deviation of the eye. One month later there were no detectable cranial nerve signs.

CASE 7 A 66-year-old widow injured her chin just to the left of the centre on a wooden stake in her garden. The following day her face was swollen and she received tetanus toxoid. Three days later the wound was obviously infected and she was started on erythromycin. The following day a piece of wood discharged from the wound, and one day later she developed a left facial weakness and mild trismus. Four days after the onset she had dysphagia, bit her tongue while attempting to drink, and was admitted to the Respiration Unit with a diagnosis of tetanus. Mild generalized tetanus was present, and in addition nystagmus and a left facial weakness; the left orbicularis oculis muscle was weak and there was no movement of the facial muscles rou $\mathrm{n} 1$ the left side of the mouth. Tracheostomy was performed and the wound explored under antitoxin cover of about 10,000 units of hyperimmune human anti-tetanus plasma. She was sedated with diazepam, requiring a maximum dose of $7 \mathrm{mg} / \mathrm{kg}$ body weight $/ 24$ hours to prevent spasms. She gradually recovered and after 
29 days in hospital she was discharged with a minimal weakness of the lower part of the left side of the face. When seen two months later no cranial nerve signs were present.

Electromyography 10 days after the onset, when the facial paralysis was still present, showed normal peripheral conduction times in both facial nerves, and normal reflex latencies. Maximum voluntary effort produced normal complex activity on the clinically unaffected side, and only moderately complex activity on the affected side, suggesting fallout of motor units. These findings are compatible with a lesion of motor neurones in the facial nucleus. The EMG was repeated after five months when maximum voluntary effort now produced normal complex activity on both sides, and on the previously affected side motor units were now also normal.

\section{DISCUSSION}

In this series, the seventh cranial nerve was affected in six of the seven patients. Ptosis occurred once, external ophthalmoplegia once, and hypoglossal paralysis once. Nystagmus was present in two cases. The 94 cases reviewed by Brown (1912) mostly had facial paresis, but eight had ptosis and two had paralysis of the tongue; only one had nystagmus. Out of a total of 82 cases reported by Patel et al. (1960), Vakil et al. (1964), and Jaffari (1966), 65 had facial paresis, which was bilateral in two; 11 had ptosis, and five had some degree of external ophthalmoplegia. One case was reported as having nystagmus, but none with paralysis of the tongue. Wetzel (1942), reviewing 30 cases of tetanus following injury to the eye, showed that in 18 that developed cranial nerve palsies, it was the seventh nerve in 14; ptosis was present in three, and external ophthalmoplegia in four. Nystagmus was mentioned by Sigwald (1946) in a single case report.

Of our total of 12 cases in which the presumed site of infection was in the head, seven were known to have developed cranial nerve palsies and no cranial nerve palsies occurred in other circumstances. Three of these and two of the remaining five, developed severe tetanus, which constitutes a similar proportion to the overall series. Creech, Glover, and Ochsner (1957) and Patel and Mehta (1963) in large series found little evidence that the site of injury affected prognosis in any way. It is general experience that injury in the head and neck more frequently results in cranial nerve palsies than injury at all other sites. However, in the same combined series of 82 cases mentioned above, a site of entry other than in the head or neck was implicated in 33 cases.

All the cases of tetanus with cranial nerve palsies described in this paper survived, while the overall mortality of all cases of tetanus was $21.5 \%$. Mortal- ity in tetanus is variously reported. In India tends to be high. Laha and Vaishya (1965) reported a $50 \%$ mortality in a series of 1,000 cases; Pate and Mehta (1963) 43.7\% in 2,007 cases; Ku\& Shen, Yeh, and Hung (1963), in Formosa, $31 \%$ in 306 cases; and Creech et al. (1957), in New Orlean\$? $30.6 \%$ in 558 cases. Bagratuni (1952) left the impression that the outlook in cephalic tetanus was worse than for that unassociated with craniat. nerve palsies, since earlier reports had suggeste a high mortality (Brown, 1912, 53\% and Wetze 1942, 80\%). However, in recent reports (Pate et al., 1960; Vakil et al., 1964; Jaffari, 1966), the mortality does not seem to be appreciably affecteg either way by the presence of a cranial nerve palsy Mortality in cephalic tetanus and ordinary tetanus. is determined by the severity of the generalize $\mathbb{P}$ disease, with little prognostic significance to be attached to a cranial nerve palsy. As far as this itself is concerned, where follow-up reports are available, complete recovery appears to be the rule although the facial paresis may persist for some time (Bagratuni, 1952). This would be confirmedu by the progress of the cases discussed here.

Some debate exists as to the site of the lesionfif cephalic tetanus. A previous report of elector myography of the facial nerve in this condition confirmed our finding that nerve conduction tifes are normal (Bagratuni, 1952). It is significant 值at

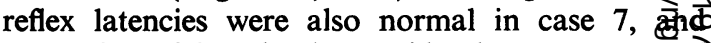
suggestive of inactivation, evidently temporary, anterior horn cells in the facial nucleus. Clinicab impressions in ophthalmoplegic cases (Jayme Goyaz, 1941; Bagratuni, 1952; and in our case 5 are suggestive of a nuclear lesion. Debate is probablo hottest as regards the pathology of these lesionsp Brown (1912) quoted the work of several turn-of the-century German pathologists who had describe $\bar{\Phi}$ brain-stem nuclear changes in tetanus, and his own view was that the syndrome was of nuclear origin Baker (1943) quoted Elischer (1876) who had described changes in the cranial nerve nuclei wit peripheral chromatolysis in fatal cases of tetanus? He then went on to describe 12 cases in whic definite degenerative changes were seen in moto

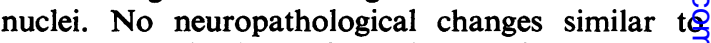
those he described were found in any of the necropsy material of the present series, and no changes were noted in the brain-stem which might have beep attributable to tetanus toxin. Montgomery (1961 reported on a detailed histological study of the central nervous system in nine fatal cases of tetanus and was unable to confirm the earlier findingso It is reasonable to conclude that the brain-stenw motor nuclei are the site of the lesion, which ip some cases at least is only temporary; and that io 
is a biochemical one, not always amenable to ordinary histological techniques. The centripetal transport of tetanus toxin along nerve fibres opposed by Abel, Evans, Hampil, and Lee (1935) would nevertheless provide an accurate localization of its effect within the nucleus, leading to the segmental distribution of facial weakness often observed (cases 3 and 7).

The term cephalic tetanus should refer to a variant of tetanus associated with nuclear cranial nerve palsies, and also commonly associated with injury to the face. Neither of these features affects severity or mortality, and prognosis for recovery of nuclear function is excellent.

\section{SUMMARY}

One hundred and seven cases of tetanus were treated at the United Oxford Hospitals between 1950 and 1968. A total of 12 cases had a presumed site of entry in the head. Seven of these developed a cranial nerve palsy.

All the patients with evidence of a cranial nerve palsy survived, and all the nerves made a clinical recovery. Mortality in the overall series was $21.5 \%$.

Some reasons are given for thinking that the cranial nerve palsies may be due to a nuclear rather than a peripheral lesion.

I wish to thank Dr. B. Shahani, who kindly performed the neurophysiological studies in case 7, Professor A. Crampton-Smith for stimulating my interest in the management of tetanus, and Dr. J. M. K. Spalding for his helpful advice with preparation of this paper.

\section{REFERENCES}

Abel, J. J., Evans, E. A., Jr., Hampil, B., and Lee, F. C. (1935). Researches on tetanus: II; The toxin of the bacillus tetani is not transported to the central nervous system by any component of the peripheral nerve trunks. Bull. Johns Hopk. Hosp., $56,84-114$.

Bagratuni, L. (1952). Cephalic tetanus: with report of a case. Brit. med.J., 1, 461-463.

Baker, A. B. (1943). Medullary involvement in tetanus. Amer. J. Path., 19, 709-723.

Bell, Sir C. (1830). Case of trismus, conjoined with paralysis of the face, in The Nervous System of the Human Body. Appendix XLIV. 2nd ed. Longmans: London.

Brown, A. J. (1912). Cephalic tetanus: with report of a case. Ann. Surg., 55, 473-484.

Creech, O., Glover, A., and Ochsner, A. (1957). Tetanus: evaluation of treatment at Charity Hospital, New Orleans. Louisiana. Ibid., 146, 369-381.

Jaffari, S. M. H. (1966). Cephalic tetanus. Indian Practit., 19, 389. 396.

Jayme-Goyaz, G. G. (1941). Cephalic tetanus following injury to the eyeball. Amer. J. Ophthal., 24, 1281-1299.

Kuo, T. P., Shen, Y. S., Yeh, P. E., and Hung, C. C. (1964). Tetanus: clinical analysis of 300 cases in Taiwan. J. Formosan med. Ass., 63, 253-264.

Laha, P. N., and Vaishya, P. (1965). Tetanus: a study of 1000 cases. J. Indian med. Ass., 44, 422-436.

Montgomery, R. D. (1961). The cause of death in tetanus. W. Indian med.J., 10, 84-102.

Patel, J. C., Dhirwani, M. K., and Mehta, B. C. (1960). Cephalic tetanus. Indian J. med. Sci., 14, 695-699.

, and Mehta, B. C. (1963). Tetanus: a study of 2007 cases. Ibid., 17, 791-811.

Pollock, G. (1847). A case of tetanus following a lacerated wound of the cornea. Lancet, 1, 589-590.

Rose, E. (1869). Ueber den Starrkrampf, in Handbuch der Allgemeinen und Speciallen Chirurgie, Band I, Abteilung, 2A, 5, 86-90. Edited by F. V. Pitha and T. Billroth. F. Enke: Stuttgart.

Sigwald, M. J. (1946). Tétanos céphalique d'allure primitive à forme polio-encéphalitique avec pseudo-paralysie de la latéralité. Rev. Neurol., 78, 584-586.

Vakil, B. J., Tulpule, A.,Iyer, S. N., and Tulpule, T. H. (1964). Cephalic tetanus. J. Indian med. Ass., 42, 212-219.

Watkins, A. L. (1939). Facial paralysis in cephalic tetanus. Arch. Neurol. Psychiat. (Chic.), 41, 788-792.

Wetzel, J. O. (1942). Tetanus following eye injury; report of a case; review of literature. Aner. J. Ophthal., 25, 933-944. 